\title{
Clinical Significance of Myeloid Zinc Finger 1 Expression in the Progression of Gastric Tumourigenesis
}

\author{
Guo-Qiang Lij $i^{a, b, c}$ Qing He ${ }^{a, b, d}$ Lang Yang ${ }^{\mathrm{e}}$ Shu-Bin Wang ${ }^{\mathrm{b}}$ De-Dong Yu ${ }^{\mathrm{b}}$ \\ Yu-qi He Jiang Hub Yuan-Ming Pan ${ }^{b}$ e Yun $\mathrm{Wu}^{\mathrm{b}}$ \\ anner Mongolia Medical College, Huhhot, ${ }^{b}$ Department of Oncology and Translational Medicine \\ Center, Baotou City Central Hospital, Baotou, 'Handan Central Hospital, Handan, dDepartment of \\ Endocrinology and Nephrology, CNOOC General Hospital, Tianjin, e'Department of Gastroenterology, \\ PLA Army General Hospital, Beijing, China
}

\section{Key Words}

Mzf1 • Gastric cancer • Prognosis • Precancerous lesions • Biomarker

\begin{abstract}
Background/Aims: To investigate the clinical significance of myeloid zinc finger 1 (MZF1) expression in various gastric mucosal lesions including chronic superficial gastritis (CSG), chronic atrophic gastritis (CAG), intestinal metaplasia (IM), dysplasia (DYS) and gastric cancer (GC) in comparison with normal tissues and gastric cell lines. Methods: MZF1 protein expression was detected using immunohistochemical staining in 37 CSG, 88 CAG, 77 IM, 51 DYS, 165 GC and 8 normal tissue samples. Quantitative real-time PCR (qRT-PCR) and western blotting were used to detect the level of MZF1 in gastric cell lines, 15 normal tissues and 34 GC samples, as well as 2 groups of paired primary GC and adjacent normal samples. Results: Reduced MZF1 expression was detected in most GC cells and tissues. Among the gastric tissues consisting of various stages of lesions (normal, CSG, CAG, IM, DYS and GC), MZF1 protein expression was downregulated in precancerous lesions and GC. The data from clinical analyses showed that decreased MZF1 expression was correlated with tumour invasion ( $p=$ $0.044)$, lymph node metastasis $(p=0.048)$ and poor prognosis of $G C$ patients $(p=0.003)$. Moreover, MZF1 was identified as an independent prognostic biomarker for GC patients in multivariate Cox regression analysis $(p=0.009)$. Conclusion: Downregulation of MZF1 was associated with gastric tumourigenesis, which may be a novel early predictive and prognostic biomarker in GC patients.




\section{Introduction}

Gastric cancer (GC) is one of the digestive malignancies with poor prognosis worldwide [1]. Although the incidence rate of GC has gradually declined in recent decades, GC remains a global health problem. Notably, $42 \%$ of GC patients are from China [2]. The greatest challenge for GC is that it is frequently detected at advanced stages, resulting in the loss of optimal time for treatment giving rise to poor prognostic outcomes. Therefore, it is important to discover novel candidate biomarkers for the early prediction and prognostic assessment of $\mathrm{GC}$ in patients. Currently, we have devoted great efforts to discover more reliable biomarkers to predict the clinical transformation for early diagnosis, tumour behaviour and prognosis in GC patients. MZF1, also known as MZF1A, MZF1B, ZSCAN6, ZNF42 and ZFP98, belongs to the SCAN-zinc finger (SCAN-ZF) family [3]. It was originally discovered as a transcription factor and initially studied for its role in myeloid differentiation and leukaemia [3]. Moreover, accumulating evidence has shown that MZF1 functions as a tumour suppressor inhibiting carcinogenesis, cell proliferation, invasion and metastasis in different types of tumours such as prostate cancer, cervical cancer, breast cancer and T-cell lymphoma [4-8]. Controversially, several studies have reported that MZF1 acts as an oncogene in other tumours, including lung, cervical, breast and colorectal cancer [3, 9-11].

Further studies demonstrated the critical function of MZF1 as a potential prognostic biomarker for oral squamous cell carcinoma [12]. Recently, Lee J H et al. revealed that MZF1 is a putative transcription factor that directly binds to the core region of the SMAD4 promoter and stimulates transcriptional activity to play a role in inhibiting gastric cancer [13]. Additionally, the authors illustrated that MZF1 plays a role in the migration of gastric cancer cells by promoting an increase in intracellular SMAD4 levels [13]. However, the specific role of MZF1 protein expression in GC remains unclear. In this study, we evaluated MZF1 expression during gastric malignancy and analysed the clinical significance of MZF1 and the prognosis of GC patients.

\section{Materials and Methods}

\section{Patients and samples}

From June 2011 to June 2016, 426 patients from the Baotou City Central Hospital were enrolled into a cohort study comprising 37 CSG, 88 CAG, 77 IM, 51 DYS and 165 GC, 8 normal tissues. The study cohort consisted of 331 males and 95 females (mean age, $59.95 \pm 10.62$ years; range, $30-82$ years). All the patients in this study were diagnosed and treated for the first time. The follow-up period ranged from date of diagnosis to the date of death or last date of data collection if no event was documented until June 1, 2016(follow-up range: 1-75 months). This study was approved by the Ethics Committee of Baotou City Central Hospital. Informed consent for participation in the clinical study was obtained from each patient. The date for the clinicopathological features were obtained from clinical and histopathological reports. All tissue specimens were obtained from patients who underwent gastroscopic biopsy or radical resection for gastric cancer. These specimens were formalin-fixed and paraffin-embedded, and a part of the tissues was snap-frozen in liquid nitrogen for RNA extraction. All GC patients enrolled in this study did not receive prior anticancer treatment. Histological evaluation was performed by two senior pathologists. Severity of GC was classified according to the $7^{\text {th }}$ edition tumour staging system recommended by American Joint Committee on Cancer.

\section{Gastric cell lines}

The GC cell lines were BGC823, MGC803, SGC7901, AGS and N87. BGC823, MGC803 and SGC7901 were obtained from the Cell Bank of Shanghai in China. The cell lines AGS and N87 were from American Type Culture Collection (Manassas, VA, USA). The cell line GES-1 was obtained from Peking University Cancer Hospital. Cells were routinely cultured in Dulbecco's Modified Eagle's Medium (DMEM, Life Technologies, USA) at $37^{\circ} \mathrm{C}$ in a humidified $5 \% \mathrm{CO}_{2}$ atmosphere.

\section{KARGER}




\section{Cellular Physiology Cell Physiol Biochem 2017:44:1242-1250 \begin{tabular}{l|l|l} 
DOI: 10.1159/000485454 & $\begin{array}{l}\text { (c) } 2017 \text { The Author(s). Published by S. Karger AG, Basel } \\
\text { www.karger.com/cpb }\end{array}$
\end{tabular}}

Li et al.: MZF1 is Associated with Gastric Malignancy

\section{Immunohistochemical (IHC) staining and assessment}

Rabbit polyclonal antibody against MZF1 at a dilution of 1:200 (ab64866, Abcam, Cambridge, UK) was used according to a previously reported in IHC staining protocol [4]. Immunostaining was developed using the universal immuno-peroxidase polymer anti-mouse/rabbit IHC staining reagent (ZSGB-BIO, China), and haematoxylin was used for counter staining. Antibody was omitted in the negative control slides in this study. IHC staining for MZF1 was scored based on a semi-quantitative scale (- to +++) system. Cells positively stained for MZF1 showed variable degrees of nuclear and cytoplasmic staining in the tissues. The scoring was based on the staining intensity ( $0=$ none; $1=$ mild; $2=$ moderate; and $3=$ intense) and percentage of positive cells $(0=0 \% ; 1=1 \%-25 \% ; 2=26 \%-50 \% ; 3=51 \%-75 \% ; 4=76 \%-100 \%)$. The final score of each sample (0-12) was obtained by multiplying the staining intensity with the percentage of positive cells, and tissues were ultimately defined as negative (-), score 0 ; weak expression $(+)$, score 1-4; moderate expression (++), score 5-8; and strong expression (+++), scored $\geq 9$. Tissue samples scoring (+) to $(+++)$ were considered "positive", and samples scoring (-) were defined as "negative".

\section{Quantitative real-time PCR ( $q R T$-PCR)}

In this study, all RNA was extracted from specimens using the RNeasy Mini Kit (Qiagen, Chatsworth, CA, USA). In addition, synthesis of cDNA was performed using the SuperScript First-Strand cDNA Synthesis Kit(Invitrogen). Gene expression was evaluated via qRT-PCR using the 7500 Fast Real-time PCR System (Life Technologies Corp. USA). SYBR Green was used to detect the amplified cDNA. Briefly, qRT-PCR was performed using $1 \mu \mathrm{l}$ of cDNA and $0.02 \mathrm{nmol} / \mu \mathrm{L}$ primers in a final volume of $12 \mu \mathrm{l}$ of the supermix. Primers specific to MZF1 were as follows (forward) 5'-GCGTCATCAGAGGACACACA-3' and (reverse) 5'-AACCAGGGGAGGTAGGTGTT-3'. SYBR Green (TransGen Biotech Co, Ltd, Beijing, China) was used to amplify the cDNA samples with the ABI 7500 Fast Real-time PCR system (Applied Biosystems, Carlsbad, CA, USA). The PCR mixture consisted of $2 \mu \mathrm{l}$ of cDNA and $0.2 \mu \mathrm{mol} / \mathrm{L}$ primers in a final volume of $12 \mu \mathrm{l}$ of the supermix. The PCR amplification protocol consisted of denaturation for $15 \mathrm{~s}$ at $95^{\circ} \mathrm{C}$, annealing for $5 \mathrm{~s}$ at $60^{\circ} \mathrm{C}$ and extension for $10 \mathrm{~s}$ at $72^{\circ} \mathrm{C}$ in the end. $\beta$-actin was used as the endogenous control to normalize gene expression.

\section{Western blotting (WB)}

Protein lysates were obtained using RIPA lysis buffer supplemented with protease inhibitor (Roche, USA) according to standard protocols. BCA protein assay kit (Thermo Fisher Scientific, Rockford, IL) was used to measure protein concentration in the samples according to the manufacturer's instructions. The protein samples were separated using sodium dodecyl sulphate polyacrylamide gel electrophoresis (SDSPAGE) and transferred onto PVDF membranes. The membranes were blocked with PBST $(1 \times$ PBS containing $0.1 \%$ Tween-20) with $5 \%$ non-fat milk. Then, the membranes were incubated with rabbit polyclonal antibody against MZF1 (1:1000, ab64866, Abcam, Cambridge, UK) or anti-GAPDH antibody (1:5000, Kangchen lnc. Shanghai, China) overnight. Finally, the membranes were incubated with horseradish peroxidase (HRP)conjugated secondary antibodies incubated for $1 \mathrm{~h}$ at room temperature. Images of the membraned were obtained using the Odyssey Sa Infrared Image System (Li-COR Corp. Lincoln, Nebraska USA).

\section{Immunofluorescence (IF)}

IF was performed according a standard protocol. Briefly, BGC823 and GES1 cells were seeded onto slides. The slides were fixed with $4 \%$ paraformaldehyde for $15 \mathrm{~min}$. Then, the slides were blocked with $5 \%$ non-fat milk for $1 \mathrm{~h}$ at room temperature and incubated with the primary antibody against MZF1 (ab64866, Abcam, Cambridge, UK) overnight at $4^{\circ} \mathrm{C}$. The next day, the slides were incubated with cyanine-conjugated secondary antibodies for $1 \mathrm{~h}$ in the dark. 4',6-diamidino-2-phenylindole (DAPI) staining (1:5000 vol/vol of a $5 \mathrm{mg} / \mathrm{ml}$ stock) was performed to stain the DNA. Confocal images were obtained using a confocal microscope (Olympus FV1000: Olympus Corporation, Tokyo, Japan).

\section{Statistical analysis}

Statistical values were calculated from three independent experiments. The correlation between MZF1 expression and clinicopathological features of GC patients in the different subgroups was analysed using Pearson's chi-square test (Fisher's exact $t$-test). For prognostic analysis, a univariate cox (proportional hazards) regression model was used to evaluate the association between MZF1 expression and other predictive 
variables and the prognosis of GC patients. In addition, a multivariate Cox regression model was constructed to identify the factors that could be independent prognostic predictors of survival. Overall survival curves were plotted using the Kaplan-Meier method, and the curves were compared using log-rank tests. All statistical tests were performed using two-tailed distribution, and p-value < 0.05 was considered statistically significant. SPSS 22.0 software was used to perform statistical analyses.

\section{Results}

MZF1 expression is progressively reduced in normal gastric epithelia, CSG, CAG, IM, DYS and GC tissues and cell lines

To investigate the expression of MZF1 in different stages of gastric mucosal lesions, 426 samples comprising CSG, CAG, IM, DYS, GC and normal tissues were immunostained with the antibody against MZF1. MZF1 staining was observed in the nuclei of cells. As shown in Table 1, the GC group had the lowest expression of MZF1, and expression was lower in the group of precancerous lesions, which included CAG, IM, DYS, than that in normal gastric epithelial and CSG $(\mathrm{p}<0.001)$.

The positive staining for MZF1 was present in $75.0 \%(6 / 8), 67.6 \%$ $(12 / 37), \quad 15.9 \% \quad(14 / 88), \quad 20.8 \%$ $(16 / 77), \quad 37.3 \% \quad(19 / 51), \quad 13.3 \%$ $(22 / 165)$ of normal gastric epithelia, CSG, CAG, IM, DYS and GC tissues, respectively. The IHC staining results demonstrated that MZF1 protein expression was significantly decreased progressively in normal gastric epithelia and CSG, precancerous lesions and the GC tissues (Fig.1).

We also used western blotting to validate the IHC staining results. We used 5 paired GC and adjacent normal tissues for this analysis. We found that MZF1 was expressed in normal tissues, and it was not expressed in GC tissues (Fig. 2F).

In order to confirm the expression status of MZF1 at the mRNA level, we collected 6 paired primary GC and matched adjacent normal tissues from patients. Additionally, we obtained another 15 normal gastric tissues and 34 GC tissues. Real-time PCR was used to detect the level of MZF1 expression. The results indicated that the mRNA level of MZF1 was significantly lower in GC than in that in normal tissues, and similar results were obtained at the protein level (Fig. 2A and 2F).

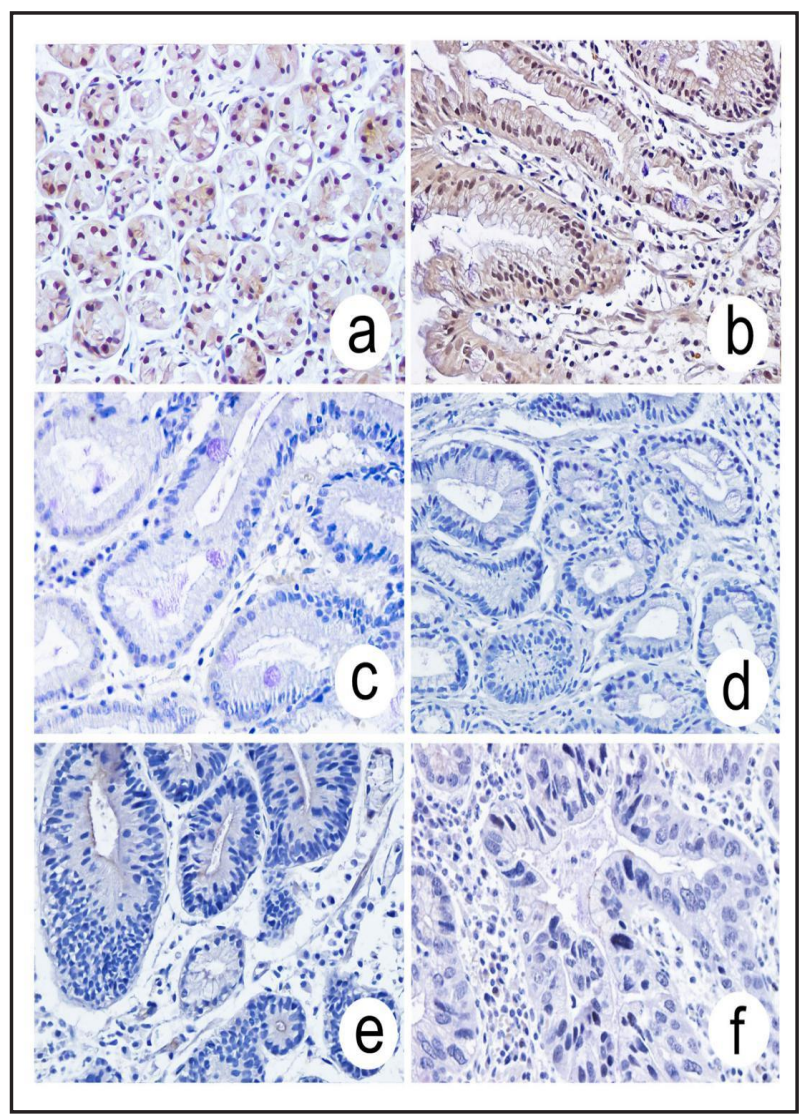

Fig. 1. Immunostaining for MZF1 in different stages of gastric mucosal lesions. a-b: Positive expression of MZF1 in normal tissues and CSG. c-f: Negative expression of MZF1 in IM, CAG, DYS and GC. 
Fig. 2. Reduced MZF1 expression in GC cell lines and tissues. a: MZF1 protein expression level was detected using western blotting (WB) in different cell lines, ${ }^{* *} \mathrm{p}<0.01$.b: MZF1 mRNA expression level in different cell lines. c: MZF1 protein was expressed in GES-1 but not in the cancer cell line BGC823 as shown by immunofluorescence and confocal microscopy. d: MZF1 mRNA expression level in 15 normal gastric epithelial tissues and 34 GC tissues. e: MZF1 mRNA expression level was measured using real-time PCR in GC tissues with matched adjacent normal tissues. f: MZF1 protein expression level was detected using WB in 5 paired tumor and matched adjacent normal tissues from GC patients.

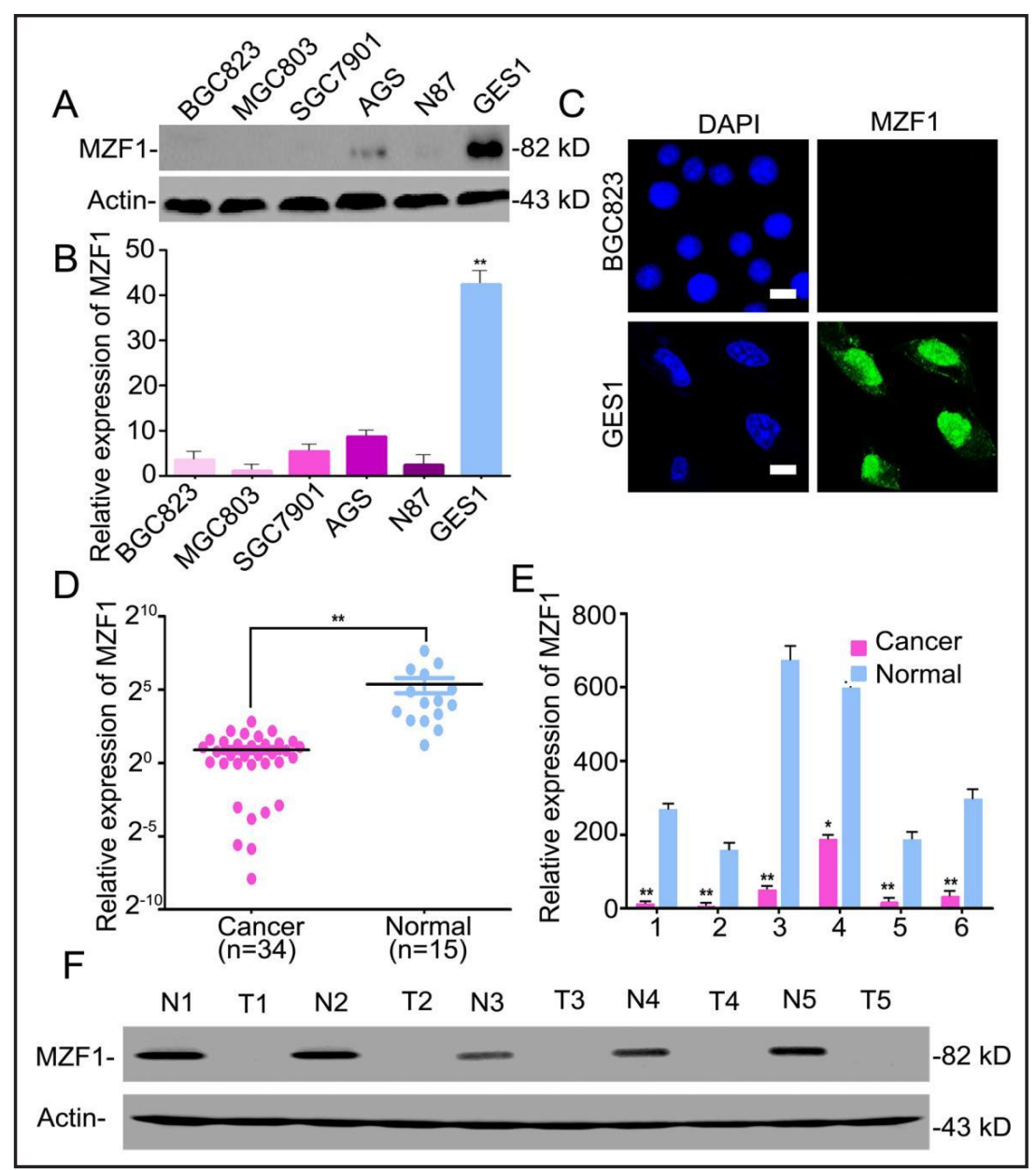

Among the gastric cell lines, five lines (BGC823, MGC803, SGC7901, AGS and N87) displayed significantly lower level of MZF1 protein compared with that in GES-1 cells (Fig. 2A). Furthermore, in GES1 cells, MZF1 stained with FITC-labeled primary antibody exhibited green fluorescence, and the nuclei were stained with DAPI (blue fluorescence); MZF1 was specifically located in the nuclei (Fig. 2C). Similar results were obtained at the MZF1 mRNA level in different gastric cell lines using real-time PCR as shown in Fig. 2B, where lower expression of MZF1 was detected in BGC823, MGC803, SGC7901, AGS and N87 cells than that in GES-1 cells. These data indicated that MZF1 was significantly decreased in GC cell lines at the mRNA and protein levels as shown using real-time PCR and western blotting analyses.

All experiments were repeated three times. As shown in Fig. 1, Fig. 2A-F and Table 1, MZF1 expression was lower in GC tissues and cell lines than that in normal tissues and cells both at mRNA and protein levels. All these results indicated that MZF1 expression decrease gradually with the progression of gastric cancer and that MZF1 expression was significantly reduced in GC.

The clinical significance of MZF1 in tumour invasion, lymph node metastasis and prognosis

Next, we aimed to evaluate whether MZF1 has any clinical significance in GC. The correlation of MZF1 expression with clinicopathological features of GC patients is shown in Table 2. Statistical analyses showed that MZF1 expression was strongly associated with invasive depth $(\mathrm{T}, \mathrm{p}=0.044)$ and lymph node metastasis $(\mathrm{p}=0.048)$ but not with other features (Table 2). Moreover, MZF1 expression level of T4 group and lymph node metastasis positive group were the lowest. 
Table 2. Correlation between MZF1 expression and clinicopathological features of GC patients

\begin{tabular}{|c|c|c|c|}
\hline Clinical features & $\begin{array}{l}\text { MZF1-negative } \\
\text { expression }\end{array}$ & MZF1-positive & $\mathrm{p}$-value \\
\hline \multicolumn{4}{|l|}{ Sex } \\
\hline Male (n=31) & 115 & 19 & \\
\hline Female (n=134) & 28 & 3 & 0.769 \\
\hline \multicolumn{4}{|l|}{ Age } \\
\hline$\geq 60(\mathrm{n}=92)$ & 77 & 15 & \\
\hline$<60(\mathrm{n}=73)$ & 66 & 7 & 0.208 \\
\hline \multicolumn{4}{|l|}{ Anatomic Stage } \\
\hline I $(\mathrm{n}=17)$ & 13 & 4 & \\
\hline II $(n=43)$ & 38 & 5 & \\
\hline III (n=96) & 83 & 13 & \\
\hline IV (n=9) & 9 & 0 & 0.230 \\
\hline \multicolumn{4}{|l|}{ Invasive depth (T) } \\
\hline $1(\mathrm{n}=7)$ & 6 & 1 & \\
\hline $2(\mathrm{n}=20)$ & 17 & 3 & \\
\hline $3(\mathrm{n}=57)$ & 44 & 13 & \\
\hline $4(n=81)$ & 76 & 5 & 0.044 \\
\hline \multicolumn{4}{|c|}{ Lymph node metastasis (N) } \\
\hline Yes $(n=46)$ & 36 & 10 & \\
\hline No $(n=119)$ & 107 & 12 & 0.048 \\
\hline \multicolumn{4}{|l|}{ Distant Metastasis (M) } \\
\hline $\operatorname{Yes}(\mathrm{n}=9)$ & 9 & 0 & \\
\hline No(n=156) & 134 & 22 & 0.609 \\
\hline \multicolumn{4}{|l|}{ Lauren's classification } \\
\hline Intestinal type $(\mathrm{n}=101)$ & 85 & 16 & \\
\hline Diffuse type(n=64) & 58 & 6 & 0.234 \\
\hline
\end{tabular}

Table 3. Univariate analyses of the relationship between clinicopathological features and prognosis of GC patients

\begin{tabular}{|c|c|c|}
\hline Clinical features & Average survival time (month) & $\mathrm{p}$-value \\
\hline \multicolumn{3}{|l|}{ Sex } \\
\hline Male $(n=31)$ & $32.97 \pm 5.60$ & \\
\hline Female $(n=134)$ & $44.45 \pm 2.90$ & 0.018 \\
\hline \multicolumn{3}{|l|}{ Age } \\
\hline$\geq 60(\mathrm{n}=92)$ & $45.91 \pm 3.42$ & \\
\hline$<60(n=73)$ & $31.17 \pm 2.68$ & 0.084 \\
\hline \multicolumn{3}{|l|}{ Anatomic Stage } \\
\hline$I(n=17)$ & $61.99 \pm 6.30$ & \\
\hline II $(n=43)$ & $44.45 \pm 4.70$ & 0.139 \\
\hline III $(\mathrm{n}=96)$ & $37.63 \pm 3.33$ & 0.015 \\
\hline IV $(n=9)$ & $24.11 \pm 5.63$ & 0.020 \\
\hline \multicolumn{3}{|l|}{ Invasive depth (T) } \\
\hline $1(\mathrm{n}=7)$ & $49.29 \pm 5.29$ & \\
\hline $2(\mathrm{n}=20)$ & $48.54 \pm 7.40$ & 0.317 \\
\hline $3(n=57)$ & $42.72 \pm 4.14$ & 0.106 \\
\hline $4(n=81)$ & $31.51 \pm 2.63$ & 0.052 \\
\hline \multicolumn{3}{|l|}{ Lymph node metastasis (N) } \\
\hline Yes $(n=119)$ & $23.58 \pm 17.65$ & \\
\hline No $(n=46)$ & $53.22 \pm 4.58$ & 0.007 \\
\hline \multicolumn{3}{|l|}{ Distant metastasis (M) } \\
\hline Yes $(n=9)$ & $24.11 \pm 5.63$ & \\
\hline No $(n=156)$ & $42.58 \pm 2.67$ & 0.228 \\
\hline \multicolumn{3}{|l|}{ Lauren's classification } \\
\hline \multicolumn{3}{|l|}{ Intestinal type $(\mathrm{n}=101)$} \\
\hline Diffuse type $(n=64)$ & $32.26 \pm 3.84$ & 0.001 \\
\hline \multicolumn{3}{|l|}{ MZF1 expression } \\
\hline Positive $(n=22)$ & $60.58 \pm 4.98$ & \\
\hline Negative $(n=143)$ & $33.55 \pm 2.39$ & 0.003 \\
\hline
\end{tabular}

We further examined the prognostic significance of MZF1 in GC. The association between survival and MZF1 expression is demonstrated in Table 3 and Table 4. In the univariate analysis, many clinicopathological features were associated with the prognosis of GC, including sex, Lauren's classification, advanced anatomic stage including II, III and IV stages, presence of lymph node metastasis and MZF1 protein expression. Lauren's classification and MZF1 expression were significantly correlated with prognosis (Table 3). Positive expression of MZF1 was correlated with longer survival, and prognosis of patients with intestinal-type GC was better than that of patients with diffuse-type GC according to Lauren's classification shown in Table 3 and Fig. 3D ( $p=0.001, p=0.001)$. 
Fig. 3. MZF1 predicted the overall survival in GC. a: GC patients with positive expression of MZF1 had better overall survival than patients with negative expression of MZF1 $(p=0.003)$; b: Patients with positive expression of MZF1 had better overall survival than patients with negative ex-
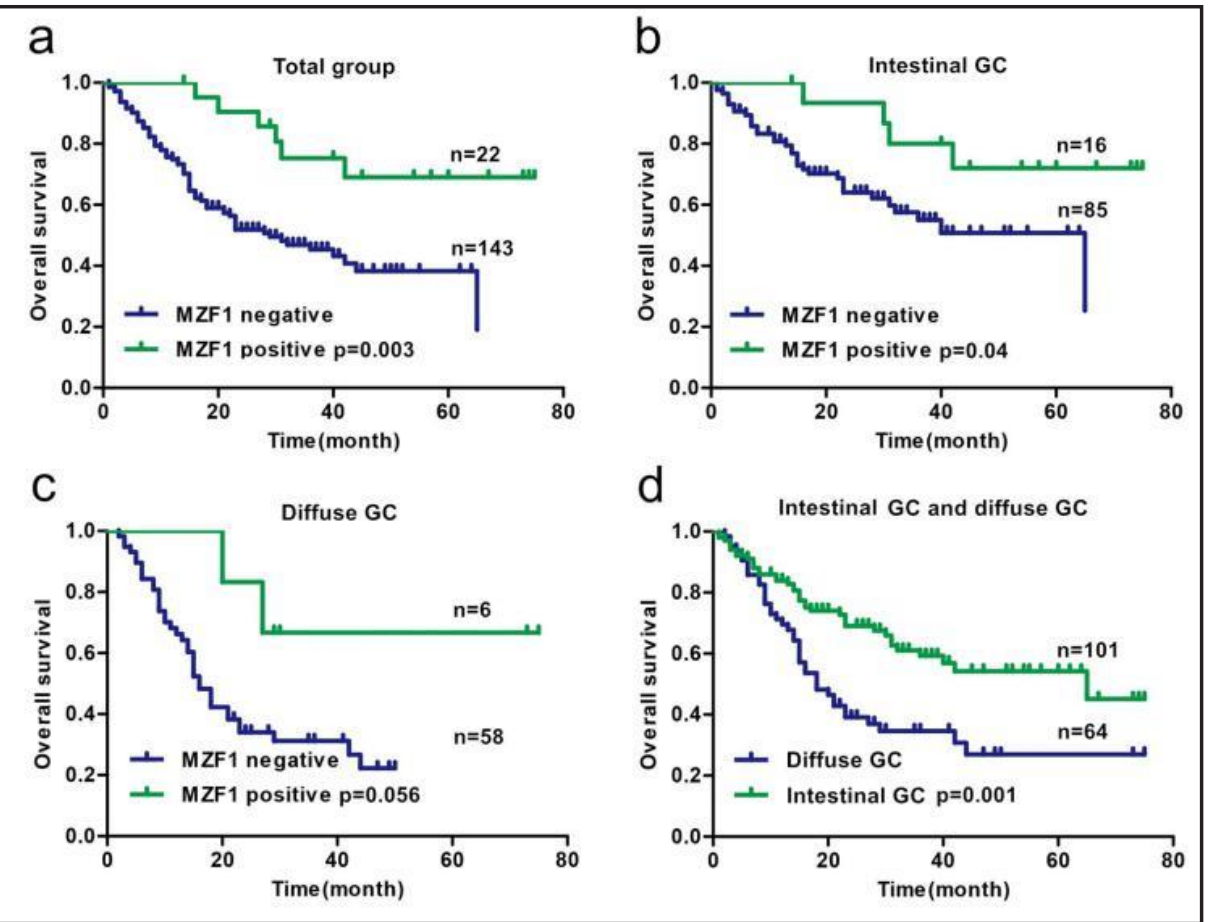

pression of MZF1 in the intestinal-type GC group $(\mathrm{p}=0.04)$. $\mathrm{c}$ : Patients with positive expression of MZF1 had better overall survival than patients with negative expression of MZF1 in the diffuse-type GC subgroup $(p=0.056)$; $d$ : Patients with intestinal GC had better overall survival that patients with diffuse-type GC $(\mathrm{p}=0.001)$.

Multivariate analyses revealed that patients with negative MZF1 protein expression had a significant decrease in overall survival. As shown in multivariate analyses, MZF1 expression was confirmed as an independent prognostic factor for overall survival (Table 4, $\mathrm{p}=0.009,95 \% \mathrm{CI}$ $=0.133-0.755)$. In addition, other clinical features had no prognostic value for survival. In Fig. 3AC, Kaplan-Meier survival curves showed that the relationship between MZF1 expression and prognosis of GC patients, and negative

Table 4. Multivariate analyses of the relationship between clinicopathological features and prognosis of GC patients

\begin{tabular}{lccccccc}
\hline Clinical features & B & Wald & p-value & $\operatorname{Exp}(\mathrm{B})$ & \multicolumn{2}{c}{$\begin{array}{c}95 \% \text { CI for } \operatorname{Exp}(\mathrm{B}) \\
\text { Upper }\end{array}$} & Lower \\
& & & & & & \\
\hline Sex & -0.507 & 3.115 & 0.078 & 0.603 & 0.343 & 1.058 \\
Age & -0.252 & 1.131 & 0.288 & 0.777 & 0.489 & 1.237 \\
Lauren's classification & 0.433 & 3.083 & 0.079 & 1.542 & 0.951 & 2.501 \\
TNM stage & 0.154 & 0.124 & 0.724 & 1.166 & 0.497 & 2.738 \\
T & 0.174 & 0.522 & 0.470 & 1.190 & 0.742 & 1.911 \\
N & 0.098 & 0.318 & 0.573 & 1.103 & 0.785 & 1.549 \\
M & -0.360 & 0.413 & 0.520 & 0.698 & 0.233 & 2.089 \\
MZF1 expression & -1.148 & 6.732 & 0.009 & 0.317 & 0.133 & 0.755 \\
\hline
\end{tabular}

MZF1 protein expression was significantly associated with shorter survival in patients with GC. Patients with positive MZF1 protein expression had better prognosis than patients with negative expression $(p=0.003$, Fig. $3 A)$. In addition, patients with positive expression of MZF1 had better clinical outcomes than patients with negative expression, especially with intestinal-type GC ( $p=0.04$; Fig. 3B). Although the $p$-value is higher than 0.05 in Fig. $3 \mathrm{C}$, 
we observed a clear trend that patients with positive MZF1 expression had better clinical outcomes than patients with negative MZF1 expression in the group with diffuse-type GC. In addition, the p-value of higher than 0.05 may have been due to the small number of samples with diffuse-type gastric cancer, as there were only 6 patients with diffuse-type GC showing positive expression of MZF1.

Collectively, these results revealed that MZF1 plays an important role as an independent prognostic predictor for GC and that the downregulation of MZF1 expression is associated with poor clinical outcomes and could thus be used for the early prediction in GC.

\section{Discussion}

In this study, we examined MZF1 expression in normal gastric epithelilal, CSG, CAG, IM, DYS and GC tissues and gastric cell lines and its correlation with clinicopathological features and prognosis. The results revealed that MZF1 expression significantly decreased progressively along the three groups from the normal and CSG group, the precancerous lesion group to the GC group. We found that MZF1 was an independent prognostic factor for patients with GC.

MZF1 expression was successively reduced in the normal and CSG group, the precancerous lesion group (IM, CAG, DYS) and the GC group. This suggested that MZF1 may be a novel tumour suppressor in GC. Reduced or negative expression of MZF1 might contribute to drive gastric tumourigenesis and poor prognostic outcomes.

Recently, similar results were reported in many solid cancers. Ko et al. reported_ that negative MZF1 expression predicted a significantly poor overall survival rate in oral squamous cell carcinoma (SCC) patients [12]. Several similar studies indicated that MZF1 could act as a tumour suppressor in prostate, cervical, breast and colon cancer and T-cell lymphoma [4, 6, 7, 14, 15]. However, contradictory evidence suggested that MZF1 could also act as an oncogene to promote tumourigenesis, tumour progression, migration and invasion, and inhibit apoptosis [3, 9-11, 16, 17]. We hypothesized that reason why MZF1 plays different roles in similar or different kinds of cancers is that MZF1 is a transcription factor that is regulated by different genes upstream of it, and it can in turn affect different target genes downstream. Hence, the underlying mechanism of regulation of MZF1 should be explored in future.

Collectively, further efforts are necessary to study the mechanism behind the silencing of MZF1 in GC, which might contribute to the understanding of gastric tumourigenesis and help in the development of precision medicine in GC treatment.

\section{Disclosure Statement}

The authors declare no competing financial interest.

\section{Acknowledgements}

Inner Mongolia Province Natural Science Foundation of China (2016MS0890), Beijing Natural Science Foundation (7172213) and Projects in the National Science \& Technology Pillar Program (2014BAI09B00, 2014BAI09B05), Inner Mongolia Province Natural Science Foundation of China (2015MS0849). YM.P. and Y.W. designed the study; GQ.L., Q.H., Y.L. and YQ.P. obtained the experimental samples; GQ.L., Q.H., SB.W., DD.Y. and J.H. conducted the experiments; GQ.L., Q.H. and YM.P. analysed the data; and GQ.L., YM.P. and Y.W. wrote the draft. All authors read, reviewed and approved the final manuscript. YM.P. and Y.W. have the primary responsibility of the final content. 


\section{Cellular Physiology Cell Physiol Biochem 2017;44:1242-1250 \begin{tabular}{ll|l} 
and Biochemistry Published onlIne: November 28, 2016 & $\begin{array}{l}\text { (c) } 2017 \text { The Author(s). Published by S. Karger AG, Basel } \\
\text { www.karger.com/cpb }\end{array}$
\end{tabular}}

Li et al.: MZF1 is Associated with Gastric Malignancy

\section{References}

1 Torre LA, Bray F, Siegel RL, Ferlay J, Lortet-Tieulent J, Jemal A: Global cancer statistics, 2012 CA Cancer J Clin 2015;65:87-108.

-2 Lin Y, Ueda J, Kikuchi S, Totsuka Y, Wei WQ Qiao YL, Inoue M: Comparative epidemiology of gastric cancer between Japan and China. World J Gastroenterol 2011;17:4421-4428.

- Eguchi T, Prince T, Wegiel B, Calderwood SK: Role and Regulation of Myeloid Zinc Finger Protein 1 in Cancer. J Cell Biochem 2015;116:2146-2154.

-4 Vishwamitra D, Curry CV, Alkan S, Song YH, Gallick GE, Kaseb AO, Shi P, Amin HM: The transcription factors Ik-1 and MZF1 downregulate IGF-IR expression in NPM-ALK(+) T-cell lymphoma. Mol Cancer 2015;14:5369.

-5 Yue CH, Liu LC, Kao ES, Lin H, Hsu LS, Hsu CW, Lin YY, Lin YS, Liu JY, Lee CJ: Protein kinase C alpha is involved in the regulation of AXL receptor tyrosine kinase expression in triple-negative breast cancer cells. Mol Med Rep 2016;14:1636-1642.

-6 Chen Y, Zhang Z, Yang K, Du J, Xu Y, Liu S: Myeloid zinc-finger 1 (MZF-1) suppresses prostate tumor growth through enforcing ferroportin-conducted iron egress. Oncogene 2015;34:3839-3847.

7 Tsai SJ, Hwang JM, Hsieh SC, Ying TH, Hsieh YH: Overexpression of myeloid zinc finger 1 suppresses matrix metalloproteinase-2 expression and reduces invasiveness of SiHa human cervical cancer cells. Biochem Biophys Res Commun 2012;425:462-467.

-8 Yi-Hsien Hsieh T-TW, Chih-Yang Huang, Yih-Shou Hsieh and Jer-Yuh Liu: Suppression of tumorigenicity of human hepatocellular carcinoma cells by antisense oligonucleotide MZF-1. Chin J Physiol 2007; 50:9-15.

-9 Mudduluru G, Vajkoczy P, Allgayer H: Myeloid zinc finger 1 induces migration, invasion, and in vivo metastasis through Axl gene expression in solid cancer. Mol Cancer Res 2010;8:159-169.

10 Deng Y, Wang J, Wang G, Jin Y, Luo X, Xia X, Gong J, Hu J: p55PIK transcriptionally activated by MZF1 promotes colorectal cancer cell proliferation. Biomed Res Int 2013;2013:868131.

-11 Hromas R, Morris J, Cornetta K, Berebitsky D, Davidson A, Sha M, Sledge G, Rauscher F, 3rd: Aberrant expression of the myeloid zinc finger gene, MZF-1, is oncogenic. Cancer Res 1995;55:3610-3614.

12 Ko CP, Yang LC, Chen CJ, Yeh KT, Lin SH, Yang SF, Chen MK, Lin CW: Expression of myeloid zinc finger 1 and the correlation to clinical aspects of oral squamous cell carcinoma. Tumour Biol 2015;36:7099-7105.

13 Lee JH, Kim SS, Lee HS, Hong S, Rajasekaran N, Wang LH, Choi JS, Shin YK: Upregulation of SMAD4 by MZF1 inhibits migration of human gastric cancer cells. Int J Oncol 2017;50:272-282.

14 Gaboli M, Kotsi PA, Gurrieri C, Cattoretti G, Ronchetti S, Cordon-Cardo C, Broxmeyer HE, Hromas R, Pandolfi PP: Mzf1 controls cell proliferation and tumorigenesis. Genes Dev 2001;15:1625-1630.

15 Horinaka M, Yoshida T, Tomosugi M, Yasuda S, Sowa Y, Sakai T: Myeloid zinc finger 1 mediates sulindac sulfide-induced upregulation of death receptor 5 of human colon cancer cells. Sci Rep 2014;4:6000.

-16 Rafn B, Nielsen CF, Andersen SH, Szyniarowski P, Corcelle-Termeau E, Valo E, Fehrenbacher N, Olsen CJ, Daugaard M, Egebjerg C, Bottzauw T, Kohonen P, Nylandsted J, Hautaniemi S, Moreira J, Jaattela M, Kallunki T: ErbB2-driven breast cancer cell invasion depends on a complex signaling network activating myeloid zinc finger-1-dependent cathepsin B expression. Mol Cell 2012;45:764-776.

17 Hromas R, Boswell S, Shen RN, Burgess G, Davidson A, Cornetta K, Sutton J, Robertson K: Forced overexpression of the myeloid zinc finger gene MZF-1 inhibits apoptosis and promotes oncogenesis in interleukin-3-dependent FDCP.1 cells. Leukemia 1996;10:1049-1050. 